\title{
NonREnEWABle Resources AND THE INEVITABILITY OF OUTCOMES*
}

Many argue that environmental degradation, particularly of the noxious pollutant and carbon-emissions variety, eventuates from a kind of prisoner's dilemma. In doing so, they suggest that it culminates in a disastrous tragedy of the commons (Hardin 1968; Gardiner 2001). Others are concerned that it arises not due to a dilemma as such, but that it is the result of externalized costs (Stern 2007), or because costs are so widely distributed, either across disconnected populations or across multiple generations (Broome 1994; Gardiner 2006; Andreou 2007). Still others have argued that we can gain a handle on the issue if we assume intransitive preferences, as with the case of the "puzzle of the self-torturer" (Andreou 2006). These are all helpful, but I believe normatively problematic, characterizations of the climate-change challenge. Each captures only one narrow dimension of what has become the "super wicked problem" of the millennium (Lazarus 2009). More importantly, each explanatory characterization carries with it a set of normative prescriptions about how best to approach the climate problem, and each implies, I think, that we ought to take action in order to mitigate climate change by reducing our emissions.

$\mathrm{I}$ argue in this paper that the release of climate-altering $\mathrm{CO}_{2}$ into the atmosphere is best understood as temporally inevitable, at least from the standpoint of moral theory. Namely, I reason that, in the absence of alternative energy technologies and robust global remediation strategies, human activity is headed toward the same end: the complete exhaustion of fossilfuel resources. In turn, as these fuels are used, the near certain outcome is that carbon, otherwise deeply sequestered in rock and sediment at the bottom of the carbon cycle, will enter the atmosphere and the terrestrial biosphere. The current climate crisis is therefore only partially characterized by each of the above factors-ranging from the consumption of nonrenewable resources to the emission and subsequent accumulation of

\footnotetext{
"Nonrenewable Resources and the Inevitability of Outcomes" by Benjamin Hale, The Monist, vol. 94, no. 3, pp. 369-390. Copyright (C) 2011, THE MONIST, Peru, Illinois 61354.
} 
carbon concentrations in the atmosphere- but these factors taken together undercut harms-based conservation arguments aimed at mitigating climate change. This, I believe, has implications for the ethical and political framework appropriate to address the climate challenge.

\section{OVERVIEW}

To understand the significance of this claim, it may help to be more concrete. It is estimated that there are at least one trillion barrels of oil remaining in the earth. ${ }^{1}$ Conservatively, if these barrels are consumed, approximately 115 billion tons of carbon will be released into the atmosphere. Generally, policy analysts and political pundits understand the climate debate as a problem for emissions: the more carbon in the atmosphere, the worse off we collectively are, though some will be worse off than others. Presumably, this means that we should cut back on what we emit.

But the ineluctable fact is that the barrels of oil in the ground are nonrenewable, and so long as there are individuals with technologies that demand oil, and so long as it is cost-effective to extract this oil, the oil will be consumed and the carbon will be released. Almost nothing can stop this. The ethical and political problem associated with emissions is therefore not a simple matter of whether and how to persuade or coerce actors, individually or collectively, to reduce their emissions. At the end of some determinate time period, approximately one trillion barrels of oil will be consumed and 115 billion tons of carbon will be released. Acknowledging this, it becomes clear that both the individual and the collective actor must make a very different decision than is typically thought - not whether to reduce or minimize harms from fossil-fuel consumption, but whether their consumption of fossil fuels for any given act would be acceptable to those who might be affected; and whether they, as actors, can accept partial responsibility for having brought about what will possibly be the greatest terrestrial upheaval since the ice age. Unfortunately, this question is masked by most (but not all) harms-based consequentialist characterizations of the carbon emissions dilemma.

By evaluating the problem of carbon emissions from the standpoint of its inevitability, in terms of individual and collective action, in terms of front-end resource consumption and back-end emissions, in terms of 
stocks and flows in the carbon cycle, we not only uncover an alternate story for our collective predicament, but we are in a better position to offer a rationale for tempering action. The appropriate course of action is not the action governed by a principle aimed at reducing harms from emissions, but the action that is governed by a nonconsequentialist principle of justified conservation. I suggest, but do not argue at length, that one can reason about what to do in the face of the climate dilemma without invoking consequentialist justificatory appeals, which have heretofore been governing much of the climate discourse.

My argument proceeds in five central steps. First, I examine several intercalated tensions in the climate challenge. Second, I outline the harmsoriented reasoning that implies that we should do what we can to mitigate climate change. Third, I explain that this approach suffers from significant causal and rational impotence objections. Fourth, I briefly address potential objections. Fifth, I offer a nonconsequentialist route around the problem of causal and rational impotence.

\section{TENSIONS}

Many before me have pointed out the extent to which the problem of climate change is particularly vexing for moral theorists. Stephen Gardiner's body of work does much to advance this case, characterizing climate change as a "perfect moral storm" (Gardiner 2001; Gardiner 2006). Richard Lazarus (2009) also recently described climate change as a "super wicked problem," drawing from the vast public policy literature on "wicked problems" and noting the extent to which climate change poses extremely thorny legal and governance challenges. No doubt, there are many vexing moral problems associated with projected climatic changes. In this section and the section that follows, what I will be calling the "harms-based approach" is, roughly speaking, the view that we should temper our individual and/or collective actions so as to mitigate climatic change brought about from emissions. I would like to focus on several internal tensions that I think together serve to undermine standard harmsbased solutions to climate change.

'Mitigation' is a technical term that can be taken to mean many things, though in the climate discourse, it refers primarily to the mitigation of 
climatic change (IPCC 2007). Among other possible interpretations, it could also refer to the mitigation of harms eventuating from climatic change, where those harms include harms or costs to others, and where mitigation efforts do little to halt the progress of climate change, but instead simply make room for affected parties to adapt. ${ }^{2}$ Since 'mitigation' and 'adaptation' are typically viewed as contrary standpoints (Pielke Jr., Prins et al. 2007; Vanderheiden 2009) the mitigation discourse maintains a substantial focus on reducing harms done to the climate, through which, then, we are to suppose that climate harms do not translate neatly into harms done to others. ${ }^{3}$

To make matters easier, I employ several important simplifying assumptions about the climate challenge. Namely, I focus this discussion primarily on carbon emissions from the burning of fossil fuels. Among other things, this assumption disregards the many other greenhouse gases (GHGs) - like water vapor, ozone, methane, fluorocarbons, and nitrous oxide-associated with the burning of fossil fuels. It also disregards research suggesting that GHGs are not the sole anthropogenic driver of climatic change. While not a complete characterization of the climate challenge, focusing on carbon is nevertheless a strategy widely employed by some of the most prominent authorities (IPCC 2007).

Consider briefly the complexity of the climate problem.

\subsection{Tension one: individual and collective}

As most of the explanatory models indicate, there are direct conflicts between individual and collective action. Certainly, the most prevalent explanatory model understands the climate problem as one of transitive preferences shared between individual actors. The classic tragedy of the commons explains how individual actors, acting according to their own self-interest, can serve to undermine their collective self-interest (Hardin 1968). Not surprisingly, many scholars consider the climate-change conundrum as a massive scale tragedy of the commons (see Gardiner 2001). The widely trumpeted Stern Review Report, for instance, begins from the premise that climate change is the "widest and greatest ranging market failure" in human history (Stern 2007). This model of the climate problem introduces normative fixes of a Hobbesian or Coasian nature, and calls upon us to coordinate with other citizens and nations of the world to achieve binding and enforceable Kyoto-style agreements. 
By contrast, the "puzzle of the self-torturer," first introduced by Warren Quinn and later adapted by Chrisoula Andreou to apply to environmental damage, offers a somewhat different explanation for climate change (Quinn 1993; Andreou 2006). Where prisoner's dilemma logic relies on the observation that one state of the world is transitively preferable to another state of the world, and therefore understands climate change as merely a problem of coordination, the puzzle of the self-torturer demonstrates that these preferences needn't be transitive. Communities can sometimes act as individuals, and when they do, if preferences are intransitive, it is not clear that the community will get its preferenceordering right. By taking incremental steps from one state of the world to the next state of the world, we can collectively drive civilization off of a cliff . . . even if we coordinate.

The puzzle of the self-torturer stems from the imperceptible harm of shifting from one state of the world to the next state of the world in pursuit of immediate rewards. Here is the puzzle of the self-torturer in Quinn's words, with clarifications in brackets by Andreou:

Suppose a medical device that enables doctors to apply electrical current to the body in increments so tiny that the patient cannot feel them. The device has 1001 settings: 0 (off) and $1 \ldots 1000$. Suppose someone (call him the selftorturer)...[has] the device, in some conveniently portable form, attached to him [and is aware of] the following conditions: the device is initially set at 0 . At the start of each week he is allowed a period of free experimentation in which he may try out and compare different settings, after which the dial is returned to its previous position. At any other time, he has only two options - to stay put or to advance the dial one setting. But he may advance only one step each week, and he can never retreat. At each advance he gets \$10,000 (Quinn 1993; Andreou 2006).

Minor variations between contiguous shifts in the universe from one state to the next are barely perceived by the self-torturer, and thus do not enter into preference calculations when set against immediate benefits, even though the self-torturer can be clearly aware that major variations between noncontiguous states of the universe would likely shift preference calculations. Thus, it is not clear that simply coordinating individual actors can ever be enough to stem the tide of disaster. This view writes a somewhat different normative prescription, suggesting that we can take action to avoid disaster by taking into consideration the needs of future 
generations, reordering our preferences, and abandoning dubious economic techniques like the discount rate.

\subsection{Tension two: front-end and back-end}

Many environmental problems involve either a front-end or a backend focus, usually with an emphasis more on one than the other. Sometimes concerns stem from the extraction of renewable or nonrenewable resources, as with silicon, fisheries, or forests. These cases involve concerns primarily over whether and the extent to which we are using our resources in an equitable or a sustainable manner. Sometimes, by contrast, concerns revolve more around back-end considerations, as with emissions from industrial production, or fertilization and pesticide application for agricultural purposes. These cases involve concerns primarily over options available with regard to mitigating harms or repairing damages.

The climate challenge embodies really two central environmental foci, both front- and back-end. On one hand, it involves a substantially valuable nonrenewable energy resource. There is a limited and nonrenewable amount of fossil fuel remaining in the earth, and we must make difficult decisions about how to use that fuel. On the other hand, it involves a significant amount of GHG production, which is one of the main drivers of climate change.

What makes the global climate challenge somewhat unique is that its front-end involves a resource that otherwise has no environmental value, where what value it does have is limited primarily to its use as an energy source. ${ }^{4}$ On the back-end, climate change involves the emission of pollutants that have decidedly negative value. In this case, the scope of this negative value extends across the entire globe and affects almost everyone. Depending on where we focus the discussion, either the frontor the back-end, we are driven to slightly different considerations about what to do.

\subsection{Tension three: stocks and flows}

To understand the tension between the stock and the flow, it will be helpful to discuss the rudiments of the natural carbon cycle. Roughly speaking, carbon rests in five major reservoirs (or stocks) of the cycle: (i) the atmosphere, (ii) the terrestrial biosphere, (iii) the oceans and the hydrosphere, (iv) the sediments, and (v) the earth's core. There are feedback 
loops between each phase of the cycle, such that the atmospheric and the biospheric feedback loop exchange carbon with one another, as do the biospheric and the hydrospheric, the sedimentary and the atmospheric, and so on. See figure 1 for clarification. In an ecosystem that is not being radically stirred up by human activity, these flows are generally relatively stable and establish, over time, an equilibrium.

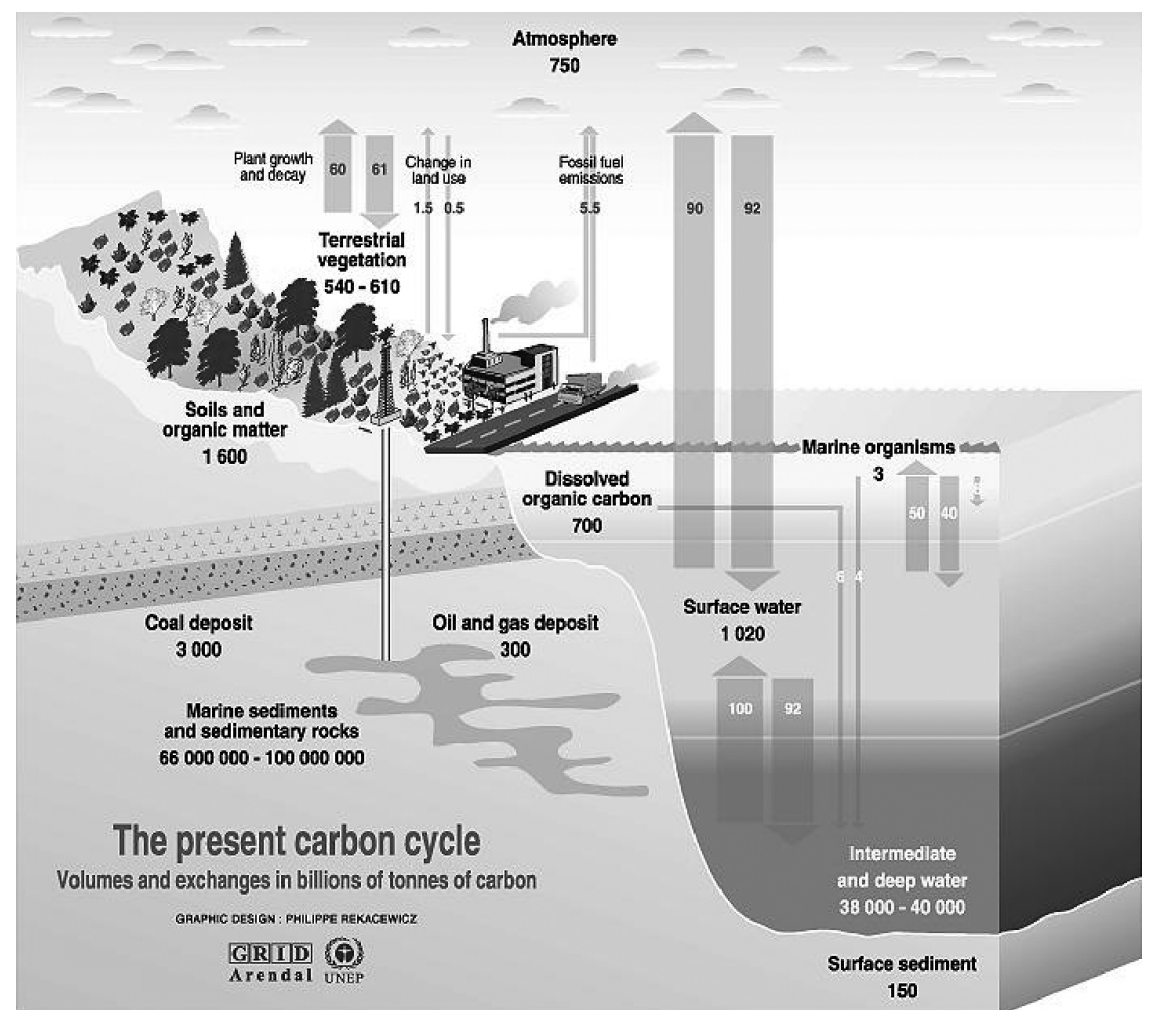

Figure 1. Feedback loops in the carbon cycle. Sources: Institute for Environmental Studies, University of Wisconsin at Madison; Okanagan University College, World Watch, Nov.-Dec. 1998; IPCC Climate Change 1995, UNEP and WMO, Cambridge University Press, 1998.

Some stocks flow relatively quickly between one another, as with the atmosphere and the terrestrial biosphere or the ocean, where transfer rates are measured in decades, hundreds or, maximally, thousands of years; but not so quickly at the lower end of the carbon cycle. The transfer rates between 
sediments and rock into the atmosphere, for instance, are measured in hundreds of thousands or millions of years.

The problem begins as quantities from these reservoirs are shifted out of stability, or when a stock in one reservoir shifts to become a stock in another reservoir. This is particularly true for reservoirs where the flow is relatively slow, which explains why some consider the burning of biomass like wood or corn for fuel to be a "green" technology, as compared with the burning of coal. Burning fossil fuels shifts carbon out of the lowest stage of the carbon cycle into the atmospheric stage, where flows between the two stages are relatively slow. Burning biomass only shifts carbon out of the top two tiers of the carbon cycle, where flows are relatively quick. Any two phases of this cycle are in a stable equilibrium with one another, thereby creating what is sometimes referred to as a 'carbon budget' between the two stocks. As carbon flows from one of the less stable stocks to a more stable stock, say from the air into the ocean, it is said to "sink" into the stock, and the ocean, then, becomes a carbon "sink." These sinks then become reabsorption mechanisms for fossil-fuel emissions to be reabsorbed by the earth. ${ }^{5}$

To some extent, the relationship is dynamic. But all is not as it seems. In a recent review article on the atmospheric lifetime of fossil-fuel carbon dioxide, David Archer and colleagues suggest that most "models agree that $20-35 \%$ of the $\mathrm{CO}_{2}$ [generated by burning fossil fuels] remains in the atmosphere after equilibration with the ocean (2-20 centuries). Neutralization by $\mathrm{CaCO}_{3}$ draws the airborne fraction down further on timescales of 3 to $7 \mathrm{kyr}$ " (Archer, Eby et al. 2009). The authors then offer this startling assessment: "climate effects of $\mathrm{CO}_{2}$ releases to the atmosphere will persist for tens, if not hundreds, of thousands of years into the future" (Archer, Eby et al. 2009). To put this a little more clearly: only between 65 and $80 \%$ of carbon released into the atmosphere is reduced in the first 200 to 2000 years. After that, there is a slight reduction over the next 3,000 to 7,000 years. Whatever else remains stays in the air for tens to hundreds of thousands of years.

As Archer and colleagues note, there is a big difference between the claim that any given carbon atom is reversed and integrated back into the carbon cycle, and the claim that carbon atoms in any given stock are reduced through a natural uptake and sequestration process. So the problem is that once carbon enters the atmosphere through the burning of fossil fuels, it 
enters the upper levels of the carbon cycle and does not follow the linearkinetics model that it is sometimes postulated. It is, in fact, subjected to the cyclical rhythms of the various atmospheric carbon budgets, but as it gets caught up in this cycle, the flows between stocks change, and the stocks of carbon react accordingly. "The mean lifetime of the elevated $\mathrm{CO}_{2}$ concentration of the atmosphere resulting from fossil-fuel combustion has been calculated to be tens of thousands of years" (Archer, Kheshgi et al. 1997).

\section{CONSEQUenCES}

Having introduced the complexity of the climate problem I turn now to my normative argument. As I've said, this paper aims at suggesting that consequentialist appeals to the harms of emissions fall subject to concerns over causal and rational impotence. In this section, it lays out the reasons why these lines of argument are so. Since $\mathrm{CO}_{2}$ emissions hang in the atmosphere for an extremely long time, and since the negative outcomes of fossil-fuel emissions are more or less guaranteed, we face a somewhat different problem than is typically thought.

Consider the general line of argument deployed in favor of mitigation. Consider first the generalized rule. Let's call it the HRR:

Harm Reduction Requirement (HRR): Given the negative outcomes associated with the burning of fossil fuels, one should either avoid burning fuels so as to avoid contributing to climate change, or burn fuels only when benefits outweigh costs.

Broadly speaking, the HRR is the standard position in the mitigation literature: we should do what we can to limit damages from fossil-fuel consumption. If taken to its natural extreme, the HRR line either (a) requires complete abstinence from the consumption of fossil fuels, (b) insists upon the integration and deployment of as-yet nonexistent carbon capture and sequestration technologies, or (c) is deeply dependent upon projections for substitutable goods or backstop resources. In the absence of adequate substitutes, the HRR mandates substantial limitations on consumption.

The HRR might then translate into a more tempered and optimistic perspective, the ARC: 
Absorption-Rate Conservation (ARC): one should use only as many fossil fuels, emitting only so much carbon, as the system can absorb (which is determined by biogeochemical processes).

Only so much carbon reabsorption can be tolerated by the system, so we must proceed cautiously and slowly, at the same rate as absorption. If we aim to emit more, then we should ensure either that there are more carbon sinks in the form of offsets, or we should follow a strictly regulated carbon budget, borrowing from the future to pay for our activities in the present.

This line of argument aims at stabilization. ARC-style arguments are common throughout the environmental literature, as almost all other ecosystems allow for a certain degree of absorption without any felt costs. Soils will absorb some pesticides or fertilizers, forests will regrow and renew, fisheries will reestablish themselves. Specifically with regard to climate change, the ARC was implied by Stephen Pacala and Robert $\mathrm{H}$. Socolow with their famous stabilization wedges, when they describe the earth as a bathtub with a very slow drain (Pacala and Socolow 2004). We should emit as much or less than is draining out, goes the thinking. The thought is that we can specify a target for emissions that does not prove problematic due to re-absorption and then distribute burdens for emissions reductions according to the appropriately just schematic.

Both lines of argument, the HRR and the ARC, are primarily consequentialist at heart; and this consequentialist orientation informs the majority of thinking about the appropriate policy response. The HRR suggests that we should conserve so that we avoid bringing about the negative impacts of fossil-fuel consumption; the ARC similarly suggests that we should conserve so that we limit damages, which we can do, it proposes, by establishing an equilibrium within a given carbon budget.

Since the ARC is arguably the most widely understood position, it will help to address it first. There is at least one core problem with most ARC thinking, and it should be clear from the biogeochemical cartoon I've sketched above: it is not the case that sequestered carbon reabsorbs into the earth over any plausibly human time frame. Most of the sequestered carbon is absorbed into sinks that are themselves part of some level of the natural carbon cycle. As these carbon budgets are naturally in a state of equilibrium, shifting carbon out of sequestered stores and into a different phase upsets this stable equilibrium, forcing the system to find a new equi- 
librium. In the case of fossil fuels, where sequestered carbon was formerly suspended in rock and sediment, it can take between two and twenty centuries for only about $70 \%$ of atmospheric carbon to sequester again. The remaining carbon will be left hanging around for hundreds of thousands of years. So the ARC is really much more closely wed to the HRR than it first appears.

This brings us to the more general mitigation rule: the HRR.

\section{The Economics of Exhaustible Resources}

There is an enormous amount of work on the ethics and economics of exhaustible resources. I cannot cover it here. It will be helpful, however, to introduce the Hotelling Rule, a principle of natural-resource economics governing the consumption of nonrenewable resources (Hotelling 1931). The Hotelling rule suggests that where a resource is exhaustible, economic pressures related to extraction will encourage suppliers of the resource to optimize extraction and conserve efficiently. They will, in other words, make concerted efforts to anticipate the market, to price according to reductions in supply, and extract their good to squeeze out the very last drop of value.

This rule is not merely theoretical, but can be observed using standard economic tools (Halvorsen and Smith 1991), though a few empirical studies suggest that oil markets behave differently than anticipated (see, for instance Kemp and Van Long 1980; Slade and Thille 1997).

Hotelling logic pushes consumption forward independently of shifts in individual behavior. Despite, though perhaps because of, pressures to price the scarce good efficiently, $\mathrm{X}$ amount of barrels of oil are consumed over some discrete, albeit unknown, time span. Slowing down emissions simply shifts the price calculus, as suppliers of oil are driven to price in an efficient manner. Conservation efforts on the front-end, then, do nothing to halt the transition of sequestered carbon into atmospheric unsequestered carbon on the back-end. In the absence of robust carbon capture and storage (CCS) technologies, alternative energy technologies, "backstop resources," or robust natural carbon sinks, exhaustible fossil fuels will continue to be consumed and carbon levels will continue to rise until the resource is priced out or exhausted. ${ }^{6}$

Here, then, is yet another somewhat odd feature of the Hotelling logic, partly related to the front-end considerations we discussed above: 
as alternative energy technologies develop, fossil fuels become less and less valuable sitting in the ground. Fossil fuels effectively reach their expiration date - so it makes sense to try to use them as fast as possible. Suppliers face increased pressures to pump fast, price optimally, and get as much oil out of the ground as they can.

One strategy to avert this outcome might be to conserve carbon-based energy stores in order to enable other technological innovations to come on line (Tahvonen 1997). Indeed, this is aggressively assumed in many of the climate projections, as with the IPCC. In fact, this may well be the overarching thrust of the emissions mitigation argument: to buy us time so that we can develop new technological fixes, including low-carbon energy technologies, effectively cheating the outcome. Some have argued that the IPCC makes dangerous assumptions when it anticipates that new technologies will spontaneously come online (Pielke Jr., Wigley et al. 2008). They demonstrate that the technologies anticipated by the IPCC modelers have yet to meet reality and likely will not develop quickly enough as countries such as China and India develop at an increasingly rapid pace.

The extraction rate is complicated not only by technological issues, but also by resource distribution issues. Prices for goods like oil are established regionally, not globally - so even if a fantastic renewable energy technology enters the market in the United States, this does not give places like Argentina or Saudi Arabia a reason to stop pumping oil. It only increases their incentives to pump until all extractable oil is consumed.

So too for policy instruments that falsely inflate local or regional prices either for oil or carbon. They simply shift global consumption patterns, dampening consumption in one part of the world only to encourage it in another part. This principle plays out when Kyoto-style policy restrictions are put into place: in the short run, pressure increases to extract and consume high-carbon fossil fuels for energy (Smulders and van der Werf 2008). Hotelling logic suggests that as external factors shift around to make oil and fossil fuels a less attractive alternative, suppliers will ramp up their efforts to get as much oil out of the ground as possible.

\section{IMPOTENCIES}

The HRR is therefore saddled with some variation of causal and rational impotence objections. If actor $\mathrm{A} \phi \mathrm{s}$ in order to avoid outcome $\mathrm{W}$, $\phi$-ing has little to no effect in thwarting W. 
Causal impotence objections have been raised frequently to object to another sort of environmentally sensitive ethical practice-vegetarianism. Roughly, the idea is that the market is not sensitive to individual level changes in demand, and thus the simple act of becoming a vegetarian does little to reduce harm to any given animal (Shafer-Landau 1994; Matheny 2002). Such objections apply also to other lumpy goods, like airplane trips and shopping malls. Indeed, philosophers have recently extended the causal impotence analysis to climate change (among others, see: SinnottArmstrong 2005; Nolt 2011).

Nevertheless, there is reason to believe that the causal impotence objection as formulated against vegetarianism fails when subject to coordinated actions on the part of multiple parties. Though it may be the case that an individual decision to refrain from eating meat produces no noticeable effect on the meat production industry, a suitably large and coordinated effort to refrain from eating meat would force an industry to shift its production schedule accordingly. Though there may be price effects generated by the felt, and thus reduced, demand for meat — say, the price per pound of meat will fall, thereby cushioning any dramatic supply impacts - depending on the elasticity of the demand for the product, the supply of the meat will also fall to some degree. By coordinating efforts, the ultimate reduction in supply undercuts causal impotence objections of the vegetarian variety.

Not so with exhaustible resources. With exhaustible resources, Hotelling logic suggests that until a backstop resource or technology can take the place of the exhaustible resource, producers will price and pump the resource until it is depleted.

Impotence objections sometimes also manifest as rational impotence, as with the apparent "paradox of voting," first noted by Anthony Downs (1957). Namely, it is almost always the case that the costs to me of educating myself about candidates and then trudging to the voting booth far outweigh the benefits of doing so. In the grand scheme of things, my vote is negligible in changing the outcome of any election, particularly at the national level. I therefore ostensibly have no reason to vote. Just as causal impotence objections are raised with regard to environmental problems, so too are rational impotence objections. Some think that I ought not to drive my car, but that my action has no noticeable effect on the surrounding state of affairs, so there are reasons for me to ignore this advice and to drive my car anyway. The private benefits to me far outweigh the costs. 
Rational impotence of the voting variety is importantly different than causal impotence of the vegetarian variety. Where causal impotence involves the removal of the intended end of the action-I aim to reduce suffering to animals, I take actions to do so, and yet my aim does not have the intended effect - rational impotence involves the extirpation of a compelling motivational reason to act. Rational impotence, in other words, uproots an agent's practical reasoning structure-I aim to elect a given official, my vote will have a negligible effect on the outcome, with great cost to me, therefore I ought not to vote. In causal impotence cases, my action is directed at the end, but thwarted midway through. In rational impotence cases, my reasoning is thwarted by other compelling reasons. In both cases, however, it is the individual who is impotent in the face of the collective; and each can be remedied by coordination and communication.

If an individual actor understands her reasons for vegetarianism or voting according to a consequentialist rationale, the argument from impotence, causal or rational, is persuasive. She ought not to vote. She is permitted to eat meat. If, on the other hand, an actor understands her reasons for vegetarianism or voting according to several possible nonconsequentialist rationales - virtue or deontological-the argument from impotence is unpersuasive. She ought to vote regardless of the extra effort to her. She has other reasons to avoid eating meat.

To be sure, consequentialists do have their arguments to alleviate concerns of causal and rational impotencies of the vegetarian and voting variety. These may include knowledge that banding together can overcome the impotence, or that one can conduct expected value calculations to approximate one's impact. The HRR argument is however beset with a somewhat different impotence objection altogether: collective causal impotence. Any single act of refraining from burning fossil fuels has no impact whatsoever on the overall outcome, unless the restraint against emissions is fully and completely exercised across all actors, within a very short time frame, without opportunity for fossil-fuel markets to respond to policy intercepts, and with significant enforcement and monitoring structures. Even if we all coordinate collectively to conserve our exhaustible resources, the well will eventually run dry. In cases where there is no replenishment mechanism, even collective coordination will not stop the inevitable depletion. It is neither responsive to expected value calculations nor to objections regarding coordination of or communica- 
tion among groups. The only condition under which my action would be rationally and causally potent would be when I could be guaranteed that all other actors will cooperate. Anything else will lead, eventually, in relatively short geological time, to the unleashing of all sequestered carbon.

What makes it hard to get one's mind around with this sort of causal and rational impotence is that it is certainly reasonable to assert that if everyone employs the HRR, perhaps through robust and enforceable Kyoto-style agreements, then there would be no eventual negative outcome. This is mostly true; but one would need perfect or near-perfect enforcement. Any leaks in the system guarantee the negative outcome. If I should refrain from using fossil fuels because they will run out, my refraining for that reason will only offer up a reason for someone else to use those fuels.

This, I think, calls upon us to turn away from the back-end outcome considerations and instead to look at the front-end once again - at the nonrenewability of the resource. At least when the discussion is focused on the front-end, the options are more widely open to consideration of nonconsequentialist alternatives.

\section{OBJECTIONS}

There are, of course, several objections in need of rebuttal. The first, perhaps most obvious, objection is that my argument flies in the face of many scientific and economic analyses of the issue. ${ }^{8}$ While it is true that there are elements of my claim that contradict the view advanced by some in the environmental policy community, it is not true that my position in principle contradicts the scientific or economic view. I do not argue, for instance, that climate change is inevitable. I simply suggest that one line of argument - the line that proposes that individuals ought to change their fossil-fuel consumption because individual level changes in behavior will have an impact on climate change - are subject to causal and rational impotence objections. At minimum, it is reasonable to suggest that in the case of nonrenewable resources, Hotelling logic introduces yet a slightly different, and arguably more damning, causal impotence objection than is the case with vegetarianism. Climate change thus must either be addressed by nonconsequentialism, or the committed consequentialist must bite the bullet and accept that the ARC fails. 
More substantively, however, one might object that if the focus of the discussion is narrowed to include "harm done to the climate from carbon" as I propose above, then the impotence objections are potentially stalled by substitute goods. If there is some other backstop resource - call it 'schmarbon'- that has functionally similar greenhouse gas properties to carbon, then it may be the case that stretching out our use of carbon will slow the adoption of schmarbon. Certainly, this objection has merit. If there are other resources that are deleterious to climatic systems, then perhaps we do have strong consequentialist reasons to limit our use of carbon. For the purposes of teasing out the impotence objections, however, I propose constraining the analysis to focus primarily on carbon. To assume schmarbon is, effectively, to assume that the supply of carbon is not finite. After depleting our schmarbon, we might then just shift to flarbon, glarbon, and blarbon.

One might also object that perhaps the degree of harm to the climate due to the slightly longer consumption timeframe-again, I am not addressing the general plausibility of this claim, but rather importing it from the climate literature-will make a difference with regard to the inevitability of the outcome. Even if the difference in harm to the climate is fractional, say the climate is harmed by $99.999999 \%$ in a conservation case, where it is completely harmed $100 \%$ in a depletion case. This difference alone would be enough to say that there is no problem with causal impotence. But it seems to me that this is not the case. Conceive of the climate as something that can be broken, like a clock. Whether the clock is broken into 1000 pieces or 1001 pieces doesn't really matter with regard to the brokenness of the clock. It is still broken.

A second variation on this objection may suppose that the conservation case asymptotically approaches the depletion case, so that the harm is nevertheless still fractional. If the harm is fractional, then over many hundreds of years, the difference in this fraction will add up to be substantial. I think the same response applies.

A third variation on the same objection may suggest that by conserving now, we might delay harm to the climate and thus gain value for the period leading up to the eventual harm of the climate. If the climate reaches $1000 \mathrm{ppm}$ in year 2100 or if it reaches $1000 \mathrm{ppm}$ in year 2110, the difference is still ten years. Someone may agree that the outcome will be the same in either case, but in the latter case, we will have been spared ten 
years of enjoyment. But consider: if this is true, then it is likely also true that the earth will re-equilibrate at approximately the same rate, so if it reaches $1000 \mathrm{ppm}$ in 2100, it may return to $300 \mathrm{ppm}$ in 20,000 years, reequilibrating in the year 22,100; whereas if it reaches $1,000 \mathrm{ppm}$ in 2110 , it will still take 20,000 years to re-equilibrate, returning to $300 \mathrm{ppm}$ in the year 22,110 . The full span of re-equilibration will be offset by ten years. In the grand scheme of things, the difference is not so great that any individual or collective action is not rightly characterized as impotent.

\section{Solutions}

As I've said, the point of the above discussion is not to assert that the anticipated outcomes are in fact inevitable - there are, after all, other measures that may help stem the tide of climate change, including the development of alternative energies, the introduction of global economic mechanisms that increase the price of carbon or reduce demand, thus shifting the floor price, or the deployment of wide-scale carbon capture and sequestration technologies - but to claim that consequentially derived conservation principles rooted primarily on back-end considerations about damage to the climate are self-undermining and subject to crippling causal and rational impotence objections. Despite this, harm reduction is the standard position advocated by a flotilla of advocacy NGOs, as well as suggested in the IPCC report and the Stern Review Report (Stern 2007). As a result, the discussion in the environmental justice literature has focused predominantly on the distribution of burdens or on the extent to which equity models ought to center on the absorptive capacity of the atmosphere (Vanderheiden 2008). In doing so, it has tended to overshadow arguments regarding legitimacy of proposals about how to distribute remaining energy reserves.

So what do we need? We need arguments for conserving fossil-fuel resources in an intelligent and ethically justified way, not for simply cutting back on emissions, and not simply for determining how much any given nation ought to be allowed to emit. These arguments exist, of course, and can be found, so I believe, by looking at how we dole out the remaining energy reserves and whether we can justify our distribution of those reserves. What is needed more than a back-end consequentialist argument for slowing down the rate of emission is a front-end nonconse- 
quentialist argument for acting rightly even if the projected results do not come to pass. ${ }^{8}$ Avoiding complications instigated by HRR may lead to actions that permit for change, and perhaps even harmful and damaging change, but do so in the most equitable and just way possible.

What, then, is the alternative? Consider briefly how the voting paradox can be elided by appeal to nonconsequentialist reasoning. The reason that one should participate in democracy has little to do with one's instrumental objectives, but more to do with whether one is offering up the right reasons. One should participate in democratic deliberation and in voting regimes because it is a constitutive (or formal pragmatic) requirement of being a citizen. So too for the rationale guiding responses to climate change. It is plain, for instance, that some parties will be beneficiaries of global climate change, in perhaps a variety of unimaginable ways. Some may be liberated from otherwise crippling environmental conditions. Equivalently, some parties may lose a great deal in a global shift brought about by further resource consumption. Some may have their rights trampled. To focus strictly on the consequences is not sufficient. Rather, the climate question must be posed differently, maybe more like this: to what extent can I (we) justify $\phi$-ing in the face of evidence that I (we) will be complicit in bringing about W?

This line of reasoning cannot make justificatory appeals strictly to consequences - as any $\phi$-ing involves complicity in the bringing about of $\mathrm{W}$-but must instead defer to questions about whether $\phi$-ing is justifiable in some socially productive or contributory way. Maybe I aim to stretch out resources and invest in alternative energies; maybe I aim to facilitate the expansion of opportunities or capacities to adapt. To establish the legitimacy of this claim, I must turn to those who will be affected by my action. I must inquire into their concerns and permit that the reasons that guide me may be unacceptable.

The justificatory engine, in this case, is the extent to which the use of oil could or would be acceptable to all, to the extent to which the outcome of any particular action would be tolerated. We may well find that the development of humanitarian infrastructure (wherever it is needed) can be justified for human-rights reasons, where the continued and extensive consumption of fossil-fuel resources for the distribution of luxury goods (wherever they are consumed) cannot be justified. For reasons that I cannot cover here, the contours of the appropriate nonconsequentialist justifica- 
tion will be contingent upon the extent to which the reasons that underwrite the actions can be validated by as wide a community as possible.

\section{CONCLUSION}

It is tempting to think that we should frame the climate challenge as a question about how to turn the tide of calamity. When we approach the problem in this manner, we focus primarily on the back-end (or the emissions-end) of the problem and raise questions about individual actions versus collective actions. This leads us to engage in complex explanatory disputes about the root causes of the problem, seeking desperately to isolate the best solutions. But I have argued in this paper that this emphasis on the back-end of the problem dramatically misunderstands the challenge, and therefore dramatically misunderstands the ethical questions before us. Moreover, this undue emphasis on the backend has the effect of crowding out nonconsequentialist normative approaches that otherwise could play a more important role in the discussion. Since long-term damages (to the earth's climate) are more-or-less guaranteed by emissions, we must instead focus on the front-end, on the consumption end, to determine the right course of action. Put differently, at both the individual level, where interests are understood as transitive, and at the collective level, where interests are understood as intransitive, the inevitability of the outcome changes the logic that underwrites and motivates action. As a result, the moral reasoning that addresses the logic must be altered as well.

The solution to this problem, I think, lies in a different justificatory approach for environmental action altogether. What is needed is a nonconsequentialist justification akin to the justificatory apparatus reflected in structures of democratic deliberation, where individual actors seek reasons to do the right thing, and as with voting paradoxes, know full well that their action will have a negligible effect on a near-certain outcome. One possible approach is therefore to understand the climate challenge as a question about the justifiability of individual acts of fossil fuel use.

The question that must be asked is whether we are justified in $\phi$-ing in the face of evidence that we will be complicit in bringing about W. Insofar as this is the case, the debate of more central importance is about how to distribute and allocate scarce fossil-fuel resources in a way that 


\author{
will be acceptable to all, not about how to share or distribute the burden \\ of climate mitigation. ${ }^{9}$
}

\author{
University of Colorado, Boulder
}

Benjamin Hale

\title{
Notes
}

* This essay has been revised from its originally published version.

1. This estimate is fairly fuzzy and does not include reserves in tar sands or oil shale. At the same time, the number of barrels in the ground is irrelevant. No matter if it is one trillion barrels or ten trillion barrels of extractable fossil fuels, the argument should hold. OPEC: http://www.opec.org/library/FAQs/PetrolIndustry/q1.htm

2. This alternative position is ostensibly taken in many places, though it is frequently accompanied by a pernicious equivocation on the meaning of 'mitigation' and a false dichotomy between options. For instance, authors will often introduce climate mitigation policies as though they are in place to mitigate harms from climate change. They will then abruptly slide into a discussion of the costs of mitigation efforts to reverse climate change versus the projected economic costs of climate change (for examples of this, see the Stiglitz citations and the Stern Review Report).

3. I will ignore, for the time being, concerns about the extent to which the climate or the earth can be 'harmed'. Clearly there are rich theoretical objections to claims about damage to the climate. Nevertheless, this is the dominant stance in the climate change discourse: that we must do what we can to halt or reverse climate change.

4. Plainly, there are other goods that exhibit the same lack of value sitting in the ground, including precious metals, but few exhibit also this decidedly negative widespread back-end disvalue.

5. For a nice explanation of this process, see: http://www.pmel.noaa.gov/co2/OCO_Report/

6. Note that this is not the case with renewable resources like trees and forests. In these cases, we are not limited by our stock of the resource, and we can replant our resources to cause a carbon drawdown.

7. Thanks to Avram Hiller, Eric Chwang, and David Boonin for these suggestions.

8. Consequentialist appeals can, of course, also offer action-guiding rationale regarding front-end consumption concerns. Clearly, a policy aimed at redistributing resources to allow some populations to adapt to climate change, or one aimed at redistributing resources to allow alternative energy structures to come on line, both appeal to consequences.

9. Special thanks to two referees for The Monist, and to Simon Caney, Eric Katz, Paul Baer, Avram Hiller, David Boonin, and Eric Chwang for offering helpful comments on earlier versions of this paper.

\section{REFERENCES}

Andreou, C. 2006. "Environmental Damage and the Puzzle of the Self-Torturer," Philosophy \& Public Affairs 34(1): 95-108. 
2007. "Environmental Preservation and Second-Order Procrastination," Philosophy \& Public Affairs 35(3): 233-48.

Archer, D., M. Eby, et al. 2009. "Atmospheric Lifetime of Fossil Fuel Carbon Dioxide," Annual Review of Earth and Planetary Sciences 37: 117-34.

Archer, D., H. Kheshgi, et al. 1997. "Multiple Timescales for Neutralization of Fossil Fuel CO2," Geophysical Research Letters 24: 405-408.

Broome, J. 1994. "Discounting the Future," Philosophy \& Public Affairs 23(2): 128-56.

Downs, A. 1957. An Economic Theory of Democracy, New York: Harper and Row.

Gardiner, S.M. 2001. "The Real Tragedy of the Commons," Philosophy \& Public Affairs 30(4): 387-416.

. 2006. "A Perfect Moral Storm: Climate Change, Intergenerational Ethics and the Problem of Moral Corruption," Environmental Values 15(August): 397-413.

Halvorsen, R. and T.R. Smith 1991. "A Test of the Theory of Exhaustible Resources," The Quarterly Journal of Economics 106(1): 123-40.

Hardin, G. 1968. "The Tragedy of the Commons.” Science 162: 1243-48.

Hotelling, H. 1931. "The Economics of Exhaustible Resources," The Journal of Political Economy 39(2): 137-75.

IPCC 2007. Summary for Policymakers. Climate Change 2007: The Physical Science Basis. Contribution of Working Group I to the Fourth Assessment Report of the Intergovernmental Panel on Climate Change. S. Solomon, D. Qin, M. Manning et al. Cambridge and New York: Cambridge University Press.

2007 Working Group III: Mitigation. I. P. o. C. Change. Cambridge and New York: Cambridge University Press.

Kemp, M.C. and N. Van Long 1980. "On Two Folk Theorems Concerning the Extraction of Exhaustible Resources" Econometrica 48(3): 663-73.

Lazarus, R.J. 2009. "Super Wicked Problems and Climate Change: Restraining the Planet to Liberate the Future," Cornell Law Review 94: 1153-234.

Matheny, G. 2002. "Expected Utility, Contributory Causation, and Vegetarianism," Journal of Applied Philosophy 19(3): 293-97.

Nolt, J. 2011. "How Harmful are the Average American's Greenhouse Gas Emissions?" Ethics, Policy \& Environment 14(1): 3-10.

Pacala, S. and R. Socolow 2004. "Stabilization wedges: Solving the climate problem for the next 50 years with current technologies," Science 305(13 August): 968-72.

Pielke Jr., R.A., G. Prins, et al. 2007. "Lifting the Taboo on Adaptation," Nature 445: 597-98.

Pielke Jr., R.A., T. Wigley, et al. 2008. "Dangerous Assumptions," Nature 452(3): 531-32.

Quinn, W. 1993. "The Puzzle of the Self-Torturer," in Morality and Action, Cambridge: Cambridge University Press, 198-209.

Shafer-Landau, R. 1994. "Vegetarianism, Causation and Ethical Theory" Public Affairs Quarterly 8: 85-100.

Sinnott-Armstrong, W. 2005. "It's Not My Fault: Global Warming and Individual Moral Obligations," Perspectives on Climate Change: Science, Economics, Politics, Ethics, W. Sinnott-Armstrong and R. Howarth, eds. Amsterdam, Elsevier: 285-307.

Slade, M.E. and H. Thille 1997. "Hotelling Confronts CAPM: A Test of the Theory of Exhaustible Resources," The Canadian Journal of Economics 30(3): 685-708.

Smulders, S. and E. van der Werf 2008. "Climate Policy and the Optimal Extraction of High- and Low-Carbon Fossil Fuels," Canadian Journal of Economics 41(4): $1421-44$. 
Stern, N. 2007. The Economics of Climate Change: The Stern Review. Cambridge, UK, Cambridge University Press.

Tahvonen, O. 1997. "Fossil fuels, stock externalities, and backstop technology," Canadian Journal of Economics 30: 855-74.

Vanderheiden, S. 2008. Atmospheric Justice: A Political Theory of Climate Change. New York, Oxford University Press.

. 2009. "Distinguishing Mitigation and Adaptation," Ethics, Place and Environment 12(9): 283-89. 